\section{3 \\ BIORMATIKA}

BIORMATIKA

\author{
Jurnal Ilmiah Fakultas Keguruan dan Ilmu Pendidikan
}

http://ejournal.unsub.ac.id/index.php/FKIP/

\title{
Pengembangan Model Pembelajaran Gerak Dasar Dengan Modifikasi Permainan Kecil Di Sekolah Dasar
}

\author{
Zuhar Ricky $^{1}$, Erit Triana ${ }^{2}$ \\ Universitas Dharmas Indonesia \\ zuharricky@gmail.com
}

\section{Info Artikel}

Sejarah Artikel:

Diterima Agustus 2019

Disetujui September 2019

Dipublikasikan September 2019

\begin{abstract}
Abstrak
Secara umum tujuan dari penelitian dan pengembangan ini adalah untuk menghasilkan model pembelajaran gerak dasar untuk pendidikan jasmani di Sekolah Dasar (SD). Selain itu penelitian ini juga bertujuan sebagai bahan ajar guru SD pada pembelajaran Penjasorkes di SD. Di Sa (Rahadian, 2018)mping itu, penelitian dan pengembangan ini dilakukan untuk memperoleh informasi secara mendalam tentang: pengembangan dan penerapan model pembelajaran bagi anak kelas IV dan V SD dan mengetahui efektivitas, efisiensi dan daya tarik hasil pengembangan pembelajaran gerak dasar. Jenis penelitian ini adalah penelitian pengembangan dengan menggunakan model pengembangan Research and Development $(R \& D)$ dari Borg dan Ball. Instrumen yang digunakan dalam penelitian dan pengembangan ini adalah kuisioner, serta instrumen psikomotorik gerak dasar. Berdasarkan hasil analisis yang telah dilakukan terhadap tanggapan/penilaian dari ahli/pelatih, hasilnya adalah 86,11 \%, dari kriteria yang ditentukan dan dapat dikatakan bahwa Model Pembelajaran gerak dasar melalui Permainan kecil ini memenuhi kriteria VALID (80\% - 100\%) sehingga dapat digunakan dan dipraktekkan dalam proses pembelajaran di Sekolah Dasar.
\end{abstract}

Keywords: Model Pembelajaran, Gerak Dasar, Permainan Kecil 
and knowing the effectiveness, efficiency and attractiveness of the results of the development of basic motion learning. This type of research is development research using the Research and Development $(R \& D)$ development model of Borg and Ball. The instruments used in this research and development are questionnaires, as well as basic motion psychomotor instruments. Based on the results of the analysis conducted on responses / assessments from experts / trainers, the result is $86.11 \%$, from the specified criteria and it can be said that the Basic Motion Learning Model through this Little Game meets the VALID criteria (80\% $100 \%$ ) so that it can used and practiced in the learning process in elementary schools.

Keywords: Learning Model, Basic Motion, Small Game

ISSN 2580-6335 (online)

ISSN 2461-3961 (cetak)

\section{PENDAHULUAN}

Pendidikan jasmani adalah bagian terpenting dari sebuah proses pendidikan. Melalui pendidikan jasmani yang diarahkan dengan baik, anak akan mengembangkan kemampuan serta keterampilan yang berguna bagi dirinya serta orang lain diantarnya adalah pengisian waktu senggang, terlibat dalam aktivitas yang kondusif untuk mengembangkan hidup sehat, berkembang secara sosial, dan menyumbang pada kesehatan fisik maupun mentalnya (Samsudin, 2008). Melalui proses pendidikan jasmani, olahraga, kesehatan diharapkan dapat mendorong pertumbuhan fisik, keterampilan motorik serta pengetahuan dari anak tersebut, yang dimulai dari pendidikan di PAUD, play grup, TK, SD, serta jenjang yang lebih tinggi.

Siswa SD merupakan salah satu aset sangat penting bagi setiap bangsa yang mana mereka kelak akan menggantikan serta meneruskan tongkat estafet pemerintahan, politik, agama, pendidikan, olahraga, dan lain sebagainya. Oleh sebab itu para siswa SD ini harus dipersiapkan dengan sebaik mungkin. Bekal tersebut di mulai dari bekal pendidikan yang baik, fisik yang kuat, serta badan yang sehat. Pendidikan sendiri mengandung makna mengubah, membina, mengarahkan dan bahkan membentuk keseluruhan dimensi peserta didik. Dengan adanya pendidikan yang baik akan mengembangkan potensi yang ada pada anak dengan memilki kekuatan spiritual keagamaan, kepribadian, kecerdasan, akhlak mulia, serta keterampilan yang perlu dalam dirinya, masyarakat dan negara.

Tenaga pendidik yaitu guru yaitu orang yang berkecimpung langsung di dalam proses belajar mengajar mempunyai tugas memberikan peluang dengan efektif sehingga apa yang diperlukan siswa sebagai peserta didik dapat terpenuhi. Dimana kita ketahui setiap anak mempunyai kelebihan serta kekurangan yang berbeda-beda. Kelebihan itulah yang menjadi tugas dari guru, untuk mengembangkannya, membimbing serta mengoptimalkan apa yang ada dalam diri anak tersebut. Dengan pendidikan jasmani di SD dapat mengembangkan bakat yang ada pada diri anak karena di dalamnya mengandung unsur kognitif, afektif serta psikimotor.

Pembelajaran di sekolah bertujuan untuk mengembangkan kemampuan gerak dasar yaitu gerak lokomotor, non lokomotor serta manipulatif. Dari ketiga jenis kemampuan gerak dasar inilah nantinya akan dapat dikembangkan, Oleh karena itu, seorang guru harus bisa memodifikasi materi yang bisa membuat siswa bergerak dan melatih kemampuan gerak dasarnya tersebut, sebaiknya anak diberikan gerakan multilateral berupa permainan kecil yang dapat mengembangkan semua unsur fisik yang ada pada anak, tidak memberikan latihan khusus kepada anak yang hanya mengembangkan sebagian kemampuan motoriknya saja tapi juga intelektualnya, (Ramadhani, 2014) 
menurut fenomena yang terjadi, remaja mengalami perubahan yang cepat secara emosional, intelektual, dan yang paling nyata secara fisik seperti bermain bola, hanya mengembangkan kemampuan keterampilan kakinya saja.

Pembelajaran gerakan lokomotor, non lokomotor dan manipulatif bisa dilakukan dengan gerakan-gerakan seperti berjalan, berlari, melompat, merayap, memanjat, untuk gerakan non lokomotor seperti mendorong, memutar badan, menggantung, peregangan, Dalam mengembangkan gerak lokomotor, non lokomotor dan manipulatif agar setiap materi yang diberikan dapat membuat anak senang melakukannya dapat dikombinasikan dengan permainan kecil yang dapat membuat anak lebih tertarik. Di samping itu seorang guru diharapkan mampu memodfikasi alat dan tempat sedemikian rupa sehingga memungkinkan terjadinya proses pembelajaran yang optimal karena pada umumnya peralatan dan ruang yang disediakan sekolah untuk pembelajaran pendidikan jasmani dan olahraga berbedabeda.

Melalui permasalahan dalam latar belakang di atas, penulis dapat mengambil kesimpulan bahwa diperlukan pengembangan pembelajaran yang dapat memberikan motivasi belajar serta manfaat, menarik dan efektif pada pembelajaran keterampilan lokomotor, non lokomotor dan manipulatif, serta memberikan kemudahan kepada guru pendidikan jasmani dalam menyampaikan materi serta pratik di lapangan. Untuk mengatasi hal tersebut perlu dikembangkan pembelajaran gerak dasar melalui modifikasi permainan kecil dalam pembelajaran PENJASORKES di Sekolah Dasar.

Menurut Tangkudung dalam (Rahadian, 2018) Penelitian pengembangan (development research) merupakan penelitian yang dipergunakan untuk menciptakan produk baru dan dapat mengembangkan produk yang telah ada berdasarkan analisis kebutuhan yang terdapat dilapangan (observasi, wawancara, kuisioner kebutuhan awal). (Sukmadinata, 2005) menjelaskan bahwa "penelitian dan pengembangan adalah suatu proses atau langkah-langkah untuk mengembangkan suatu produk baru atau menyempurnakan produk yang telah ada, yang dapat dipertanggung jawabkan". (Sugiyono, 2014) menyatakan "penelitian pengembangan atau dalam Bahasa Inggrisnya Research and development adalah penelitian yang digunakan untuk menghasilkan produk tertentu, dan mengaji keefektifan produk tersebut.

Kesimpulan dari beberapa definisi yang telah dijabarkan sebelumnya bahwa penelitian pengembangan merupakan suatu penelitian yang mendasarkan pada pembuatan suatu produk yang efektif, diawali dengan analisis kebutuhan, pengembangan produk, dan uji coba produk. Dalam hal ini penelitian yang akan dikembangkan adalah model pembelajaran gerak dasar dengan modifikasi permainan kecil untuk siswa sekolah dasar.

(Samsudin, 2008) bahwa Pendidikan jasmani adalah dengan berpartisipasi dalam aktivitas fisik, siswa dapat menguasai keterampilan dan pengetahuan, mengembangkan apresiasi astetis, mengembangkan keterampilan generik serta nilai sikap yang positif, dan memperbaiki kondisi fisik untuk mencapai tujuan pendidikan jasmani. (Supriyanto, 2012) mengemukakan pendidikan jasmani, olahraga dan kesehatan merupakan bagian dari pendidikan yang mengutamakan aktivitas jasmani dan pembinaan hidup sehat untuk pertumbuhan dan perkembangan mental, sosial, emosional yang serasi, selaras, dan seimbang.

(Jonni, 2012) Modifikasi merupakan salah satu upaya yang dapat dilakukan oleh para guru dan pengajar agar proses pembelajaran dapat dilakukan lebih mudah. Modifikasi adalah menganalisa dan sekaligus mengembangkan materi pembelajaran sehingga dapat memperlancar siswa dalam proses pembelajaran. (Kusbani, 2012) modifikasi dapat dilakukan pada alat, ukuran lapangan, aturan permainan, dan sebagainya. Dalam pendekatan modifikasi ini guru harus mampu mamanfaatkan lingkungan yang ada secara optimal sehingga dapat menumbuhkan situasi dan kondisi anak.

Belajar gerak dapat diartikan sebagai perubahan tempat posisi, kecepatan tubuh atau bagian tubuh manusia yang terjadi dalam suatu dimensi ruang dan waktu serta diamati secara 
objektif. Dalam berlajar gerak, latihan merupakan suatu proses yang paling utama dalam rangka penguasaan keterampilan (Nugraha, 2016). (Education Of, 2013) Fundamental Movement Skills (FMS) are movement patterns that involve such skills as running, hopping, catching, throwing, striking and balancing". Maksudnya keterampilan gerak dasar adalah pola gerakan yang melibatkan bagian-bagian tubuh yang berbeda seperti berlari, melompat, menangkap, melempar, memukul, dan keseimbangan. Berdasarkan penjelasan di atas dapat disimpulkan bahwa, gerak dasar dapat diartikan sebagai gerak pengulangan yang dilakukan terus-menerus dari kebiasaan serta menjadikannya sebagai dasar dari pengalaman.

\section{METODE}

Metode yang digunakan dalam penelitian ini menggunakan penelitian pengembangan. Menurut (Sukmadinata, 2005) adalah suatu proses atau langkahlangkah untuk mengembangkan suatu produk baru atau menyempurnakan produk yang telah ada, yang telah dapat di pertanggung jawabkan.

Tahap dan Langkah Penelitian Pengembangan

1. Pra Pengembangan : Pengumpulan data awal, Penyusunan proposal penelitian, Analisa kebutuhan.

2. Pengembangan : Evaluasi formatif: Uji coba awal (1) Evaluasi ini dilakukan dengan rekan sejawat, ahli yang memiliki kompetensi yang memadai dalam kontek: materi dan desain pembelajaran. Perbaikan awal Uji coba awal (2) Evaluasi pakar (Expert juggement) dengan pakar gerak (motorik), dan pakar pembelajaran pendidikan jasmani.

3. Penerapan : Uji coba lapangan Evaluasi dengan skala terbatas 30 responden, Perbaikan operasional penerapan.

Pertama kali yang ditentukan adalah sebuah ide-ide yang akan dikembangkan, dengan mengumpulkan informasi sebagai landasan pemikiran untuk membuat konsep, 2) Penulisan naskah media (rancangan produk), bentuk rancangan tersebut adalah story board, 3) Revisi produk I, revisi dilakukan oleh ahli yang bersangkutan, 4) Produksi prototipe, dilakukan dengan pengambilan gambar produk dengan media audio-visual (video), 5) Uji coba prototipe, pengujian terhadap subyek lapangan baik dalam uji coba tahap I maupun uji coba tahap II, 6) Revisi produk kedua, revisi dilakukan oleh ahli guna memperoleh hasil yang sempurna, 7) Reproduksi, penyempurnaan produk untuk menuju produk akhir yang diharapkan pada pengembangan.

Data yang digunakan pada pengembangan model pembelajaran gerak melalui permainan untuk pembelajaran PENJASORKES pada anak SD ini adalah data kualitatif, karena data yang diperoleh dinyatakan dengan kalimat dan bukan dengan angka. Sedangkan data kuantitatif diperoleh dengan cara mengubah data kualitatif ke kuantitatif dengan jalan memberi skor pada data kualitatif. Instrumen yang digunakan dalam penelitian ini adalah dengan menggunakan angket untuk analisis kebutuhan, kuesioner evaluasi ahli/pelatih atletik, kuesioner evaluasi ahli pembelajaran pendidikan jasmani dan hasil penilaian siswa.

Hasil psikomotor diperoleh dari skor total siswa dalam melakukan tes unsur-unsur gerak yang dinilai dari kebenaran dalam melakukan tiap-tiap gerak, (1) Berlari (2) Melempar. Dengan melakukan tes ini maka akan didapat hasil dari psikomotor anak dalam melakukan gerakan.

\section{Tabel 1 Kisi-kisi Instrumen Lari}

\begin{tabular}{llll}
\multirow{2}{*}{ TEKNIK } & \multicolumn{1}{c}{ INDIKATOR } & \multicolumn{3}{c}{ PENILAIAN } \\
\cline { 2 - 4 } & & & \\
\hline \multirow{3}{*}{ Teknik lari } & 1. Awalan & & \\
\cline { 2 - 3 } & 2. Keluar start & & \\
\cline { 2 - 3 } & 3. Saat lari & & \\
\cline { 2 - 3 } 4. Finish
\end{tabular}

\section{Keterangan:}

Skor 3 = Jika sesuai dengan deskripsi unsur gerak.

Skor 2 = Jika hampir sesuai dengan deskripsi unsur gerak.

Skor 1 = Jika tidak sesuai dengan deskripsi unsur gerak. 


\section{HASIL DAN PEMBAHASAN}

Hasil pengembangan model pembelajaran lari cepat melalui permainan untuk meningkatkan hasil belajar lari cepat pada anak SD kelas V ini tertulis dalam bentuk naskah atau storyboard script yang dapat dijabarkan sebagai berikut:

1. Program pembelajaran ini menyajikan pengembangan pembelajaran gerak dan permainan antara lain: gerakan pemanasan dalam bentuk permainan dasar gerak, model permainan yang disajikan dalam bentuk drama, visualisasi gerak dan melibatkan presenter. Model dalam pembelajaran ini dilakukan oleh siswa sekolah dasar terdiri dari 10 orang.

2. Kemudian caption berikutnya adalah berupa latihan pendahuluan (Pemanasan), dengan diberi melalui permainan dengan berbentuk kotak mengikuti instruksi yang ada di tengah.

3. Setelah pemanasan, kemudian berikutnya adalah penayangan inti model pembelajaran melalui permainan, yaitu permainan berbentuk angka, permainan merayap, permainan jongkok, permainan bentuk segitiga, permainan tangga tepuk dan lain-lain.

Evaluasi hasil pengembangan model pembelajaran gerak melalui permainan pada anak SD oleh ahli/pelatih atletik adalah sebagai berikut :

1. Materi pembelajaran ini perlu ditambah dengan pemanasan aktif dalam bentuk permainan dan gerak dasar yaitu gerak lokomotor dan non lokomotor.

2. Materi pembelajaran ditambah dengan memberikan materi reaksi yang diawali dengan aba-aba.

3. Penerapan pembelajaran perlu adanya peralatan yang memadai untuk membuat model pembelajaran yang bervariatif, sehingga dapat menyesuaikan dengan kebutuhan siswa serta tidak membosankan.

4. Materi atau isi dalam produk ini, ke depan agar dilengkapi dengan pola pembelajaran yang lebih banyak lagi variasinya, sehingga dapat memberikan semangat kepada guru sekolah dasar dalam mengajar dan siswa dan siswa dalam menerima pembelajaran.
5. Sebagai bahan acuan para guru sekolah dasar harus mempunyai bahan, seperti buku, modul, gambar, vidio pembelajaran agar para guru sekolah dasar menerapkannya.

Evaluasi terhadap hasil pengembangan model pembelajaran gerak melalui permainan sebagai berikut :

1. Pemanasannya kurang semua bergerak.

2. Model pengembangan bisa mengakomodasi semua siswa putra dan putri

3. Bentuk permainan bisa dilakukan di lapangan

4. Kurangi sajian dalam bentuk audio, ganti dengan sajian visual, praktik langsung sehingga memudahkan peserta untuk memahami.

5. Pemanasan menyita waktu perlu dikurangi.

6. Penutup tidak ada perlu dilengkapi.

\section{Analisis Data dari Ahli/Pelatih}

Berdasarkan hasil analisis evaluasi ahli/pelatih bahwa: diketahui jumlah total skor responden $\left(\sum \mathrm{X}\right)$ adalah 125 dan jumlah total keseluruhan skor responden $\left(\sum X 1\right)$ adalah 144 . Sehingga, persentasenya adalah $86,11 \%$. Berdasarkan hasil analisis yang telah dilakukan terhadap tanggapan dari ahli/pelatih, hasilnya adalah 86,11 \%, dari kriteria yang ditentukan dan dapat dikatakan bahwa Model Pembelajaran gerak melalui Permainan ini memenuhi kriteria VALID (80\% - 100\%) sehingga dapat digunakan dan dipraktekkan dalam proses pembelajaran di sekolah dasar.

\section{Analisis Data dari Ahli Pembelajaran Pendidikan Jasmani}

Berdasarkan hasil analisis evaluasi ahli pembelajaran penjas bahwa: diketahui jumlah total skor responden $\left(\sum \mathrm{X}\right)$ adalah 62 dan jumlah total keseluruhan skor responden ( $\mathrm{X} 1)$ adalah 72. Sehingga, persentasenya adalah $86,11 \%$.

Berdasarkan hasil analisis yang telah dilakukan terhadap tanggapan dari ahli pembelajaran penjas, hasilnya adalah 86,11 \%, dari kriteria yang ditentukan dan dapat dikatakan bahwa Model Pembelajaran gerak melalui Permainan Kecil ini memenuhi kriteria VALID (80\% - 100\%) sehingga dapat 
1. Uji coba lapangan penelitian ini hanya dilakukan pada satu tempat, yaitu SD saja

2. Adanya faktor-faktor psikologis yang diduga ikut mempengaruhi hasil penelitian yang tidak dapat dikontrol antara lain, minat, percaya diri, dan faktor psikologis lainnya.

3. Adanya faktor lain yang diduga ikut mempengaruhi hasil penelitian yang tidak dapat terkontrol seperti dari faktor kondisi fisiknya, antara lain tinggi badan, kekuatan, kelentukan dan koordinasi gerak, serta dari kondisi fisik lainnya.

4. Pembelajaran dikhususkan hanya pada pembelajaran gerak lokomotor dan non lokomotor saja.

\section{KESIMPULAN}

Berdasarkan hasil analisis yang telah dilakukan terhadap tanggapan dari ahli/pelatih, hasilnya adalah $86,11 \%$, dari kriteria yang ditentukan dan dapat dikatakan bahwa Model Pembelajaran gerak dasar melalui Permainan kecil ini memenuhi kriteria VALID (80\% - 100\%) sehingga dapat digunakan dan dipraktekkan dalam proses pembelajaran di Sekolah Dasar.

\section{DAFTAR PUSTAKA}

Education Of, D. (2013). Fundamental Movement Skill. San Fransisco: University Of Fransisco.

Gall, W. R. (2002). Educational Research An Intruduction. New York: Longman.

Jonni. (2012). Modifikasi dan Permainan Kecil. Padang: Fakultas Ilmu Keolahragaan.

Kusbani. (2012). Pengembangan Model Modifikasi Permainan Bola Tangan dan Basket Untuk Pembelajaran Pendidikan Jasmani di Sekolah MEnengah Kejuruan. Jurnal Ilmiah SPIRIT.

Nugraha. (2016). Manajemen Pembelajaran Gerak Untuk Anak . Jurnal Olahraga Prestasi.

Rahadian, R. (2018, September 2). MODEL PEMBELAJARAN SMASH BOLAVOLI PADA SISWA
SEKOLAH

MENENGAH

KEJURUAN. BIORMATIKA Jurnal

Ilmiah FKIP Universitas Subang, 04 (02), 35-47.

Ramadhani, N. T. (2014). Hubungan Antara Kepercayaan diri Dengan Citra Diri Pada Remaja Akhir. Jurnal SPIRITS, 22-32.

Samsudin. (2008). Kurikulum Pendiidkan Jasmani Olahraga dan Kesehatan. Jakarta: FIK UNJ.

Sugiyono. (2014). Metode Penelitian Kuantitatif, Kualitatif dan $R \& D$. . Bandung: Alfabeta.

Sukmadinata. (2005). Metode Penelitian Pendidikan. Bandung: PPs UPI.

Supriyanto, D. (2012). Pengembangan Model Modifikasi Permainan Sepakbola Untuk Siswa Sekolah Dasar. Jurnal Ilmiah SPIRIT.

Tangkudung, J. (2016). Macam-macam Metodologi Penelitian Uraian dan Contohnya. Jakarta: Lensa Media Pustaka. 